\title{
A tradução para o inglês de unidades fraseológicas especializadas do campo da antropologia darcyniana: um estudo da formação do habitus tradutório baseado em corpora
}

\section{Darcy Ribeiro's anthropological specialized phraseological units: a study of the formation of a translational habitus based on corpora analysis}

\author{
Talita Serpa \\ Universidade Estadual Paulista, São José do Rio Preto, São Paulo / Brasil \\ talitasrp82@gmail.com \\ Diva Cardoso de Camargo \\ Universidade Estadual Paulista, São José do Rio Preto, São Paulo / Brasil \\ divaccamargo@gmail.com \\ Marilei Amadeu Sabino \\ Universidade Estadual Paulista, São José do Rio Preto, São Paulo / Brasil \\ amadeusm@ibilce.unesp.br
}

Resumo: Com o intuito de investigar o comportamento tradutório para unidades fraseológicas especializadas (UFEs), esta pesquisa analisa um corpus paralelo composto pelas obras $O$ processo civilizatório (1968) e $O$ povo brasileiro (1995), de Darcy Ribeiro, bem como por suas traduções para o inglês, realizadas, respectivamente, por Meggers (RIBEIRO, 1968) e Rabassa (RIBEIRO, 2000). Para tanto, o artigo adota o arcabouço dos Estudos da Tradução Baseados em Corpus (BAKER, 1996, 2000; CAMARGO, 2007), da Linguística de Corpus (BERBER SARDINHA, 2004), da Terminologia (BARROS, 2004; BEVILACQUA, 2004) e da Lexicologia (CORPAS PASTOR, 2010). Quanto à análise dos dados, o trabalho se fundamenta em conceitos como capital social e habitus 
(BOURDIEU, 1980; SIMEONI, 1998, 2007; GOUANVIC, 1995, 1999, 2002, 2005) e na metodologia do programa WordSmith Tools. Os resultados apontam para a nominalização de verbos, um fator que pode alterar a compreensão do texto traduzido, principalmente no que diz respeito à interpretação do universo brasileiro, por exemplo: "integrar as massas marginais" $\rightarrow$ "integration of marginal groups"; e "transfigurar as etnias originais" $\rightarrow$ "transformation of earlier ethnos". O estudo evidencia também, o uso de normalização (BAKER, 1996, 1999) quando as unidades lexicais estão voltadas aos elementos culturais, como em: "colher as roças" $\rightarrow$ "to plant garden plots"; e "subjugar caudilhos" $\rightarrow$ "to subdue local leaders". A recorrência no uso destes aspectos permite verificar a possível formulação do habitus tradutório.

Palavras-chave: Estudos da Tradução Baseados em Corpus; Linguística de Corpus; Terminologia; Sociologia da Tradução; Unidades Fraseológicas Especializadas; Antropologia; Habitus Tradutório.

Abstract: Intending to investigate the translational linguistic behaviors in face of specialized phraseological units, this research analyzes a parallel corpus composed by the works O processo civilizatório (1968) and O povo brasileiro (1995), both written by Darcy Ribeiro, as well as by their translations into English, performed, respectively, by Meggers (1968) and Rabassa (2000). With these purposes in mind, the study is based on the framework of Corpus-Based Translation Studies (BAKER, 1996, 2000; CAMARGO, 2007), of Corpus Linguistics (BERBER SARDINHA, 2004), of Terminology (BARROS, 2004; BEVILACQUA, 2004), and of Lexicology (CORPAS PASTOR, 2010). Concerning the analysis, the investigation considers concepts as social capital and habitus (BOURDIEU, 1980; SIMEONI, 1998, 2007; GOUANVIC, 1995, 1999, 2002, 2005), as well as the methodologies offered by the program WordSmith Tools. The results pointed to the nominalization of verbs, a factor that may change the comprehension of translated texts especially in relation to Brazilian universe, such as in: "integrar as massas marginais" $\rightarrow$ integration of marginal groups; and "transfigurar as etnias originais" $\rightarrow$ transformation of earlier ethnos. An intense use of "normalization" (BAKER, 1996, 1999) was also observed when the lexical units were related to cultural marked elements, for example: "colher as roças" $\rightarrow$ to plant garden plots; and "subjugar caudilhos" $\rightarrow$ to subdue local leaders. Recurrence in using these features allowed the verification of 
a possible formulation of a translational habitus that can be associated to Translation Studies.

Keywords: Corpus Based Translation Studies; Corpus Linguistics; Terminology; Sociology of Translation; Specialized Phraseological Units; Anthropology; Translational Habitus.

Recebido em: 18 de julho de 2016. Aprovado em: 18 de outubro de 2016.

\section{Introdução}

As formulações teóricas de Darcy Ribeiro ${ }^{1}$ representam, no meio social brasileiro, uma das principais leituras responsáveis pela compreensão das problemáticas antropológicas, educacionais, políticas e sociológicas do país. A análise e teorização acerca de suas obras configuram não somente o reconhecimento de seu vasto e complexo arcabouço teórico-conceitual, mas também representam o contato com a identificação do povo brasileiro com seus princípios de nacionalidade, o que pode ser compreendido via formações históricas e etnológicas.

Darcy Ribeiro promove novos parâmetros para a constituição de um identitário de povo, reformulando objetos, termos, hipóteses e ambientações, os quais perpassam a escrita teórica e ganham ares de Literatura (poderíamos dizer "Antropológica"). O autor busca inserir um conjunto de novas categorias ao princípio da brasilidade, procurando destacar os valores da cultura miscigenada e salientando os fatores característicos típicos dos grupos sociais menos favorecidos, a saber: "negros", "índios", "mulatos", "caboclos" etc.

Nesse sentido, o processo tradutório de sua produção intelectual é uma tarefa de grande responsabilidade, até mesmo para profissionais experientes. Não basta conhecer o conteúdo linguístico e/ou o vocabulário que compõe a obra, é preciso estar a par dos conceitos, ${ }^{2}$ das disciplinas e

\footnotetext{
${ }^{1}$ Algumas das obras do antropólogo, as quais configuram suas principais teorizações, são apresentadas nas referências bibliográficas.

${ }^{2}$ Um conceito é qualquer conteúdo de uma representação que é estritamente limitado pelo pensamento de forma diferente de uma representação, não é nunca algo encontrado pronto, completo em nossa consciência, mas é essencialmente uma soma de atos de
} 
das teorizações, bem como das características socioculturais abordadas pelo pesquisador-literato, a fim de salientar seu tom crítico, as propostas de mudança e o empenho na busca pela homogeneização do povo brasileiro, características presentes na composição das obras desse intelectual.

Dentro desse quadro, o presente trabalho busca observar o comportamento linguístico ${ }^{3}$ (habitus) de dois tradutores ao lidarem com dificuldades oriundas do processo tradutório de duas obras darcynianas, as quais apresentam como característica marcante o uso de Unidades Fraseológicas Especializadas ${ }^{4}$ (UFEs) relacionadas à formação da Cultura Brasileira.

Para tanto, apresentam-se os resultados da pesquisa realizada a partir dos textos originais (TOs) em português $O$ processo civilizatório: etapas da evolução sociocultural (1968) e O povo brasileiro: a formação e o sentido do Brasil (1995), e dos textos traduzidos (TTs) para o inglês The Civilizational Process (1968) e The Brazilian People: formation and meaning of Brazil (2000), realizados, respectivamente, por Betty J. Meggers e Gregory Rabassa.

Por meio da reflexão sobre aproximações e distanciamentos na tradução para o inglês das UFEs presentes no corpus de TOs e TTs, objetiva-se, com o auxílio da Linguística de Corpus (BERBERSARDINHA, 2002, 2004), desvendar mecanismos de reinterpretação cultural com base na prática tradutória. Nesse sentido, a presente pesquisa vale-se, também, das teorias postuladas pela Sociologia da Tradução (SIMEONI, 1998, 2007; TOURY, 1978, 1995, 1999; GOUANVIC, 1995, 1999, 2002, 2005), com o propósito de investigar se há a ocorrência de um habitus tradutório generalizável para a tradução intercultural como um todo, ou se o caso das traduções de textos seminais de Darcy Ribeiro constitui uma ação social única.

pensamentos e julgamentos. [A concept is any contend of a representation which is firmly limited by thought; Unlike a representation, it is never anything encountered ready and complete in our consciousness, but is essentiallya sum of acts of thoughts or judgements.] [Todas as traduções aqui apresentadas são de responsabilidade das autoras quando os tradutores não forem mencionados.] (SAGER, 1998, p.48)

3 São entendidos por comportamentos linguísticos as escolhas léxico-semânticas e sintáticas adotadas pelos tradutores na composição de seus textos traduzidos, as quais irão determinar o conceito de habitus tradutório.

${ }^{4}$ Apresenta-se o conceito de Unidade Fraseológica sEpecializada no item Fundamentação Teórica. 


\section{Fundamentação teórica}

Nesta pesquisa, consideram-se o arcabouço dos Estudos da Tradução Baseados em Corpus (BAKER, 1999, 2000; CAMARGO, 2007), bem como alguns princípios da Terminologia (BARROS, 2004; BEVILACQUA, 2004) e da Lexicologia (CORPAS PASTOR, 2010), com o intuito de promover a análise do habitus tradutório para o campo dos estudos culturais promovidos por Ribeiro.

\section{Linguística de Corpus e Linguagens Especializadas}

No tocante aos estudos de corpora, Berber Sardinha (2004) aponta que a definição mais completa para o termo é a de Sánchez, por incorporar as características principais para a compilação de corpus em formato eletrônico:

Um conjunto de dados linguísticos (pertencentes ao uso oral ou escrito da língua, ou a ambos), sistematizados segundo determinados critérios, suficientemente extensos em amplitude e profundidade, de maneira que sejam representativos da totalidade do uso linguístico ou de algum de seus âmbitos, dispostos de tal modo que possam ser processados por computador, com a finalidade de propiciar resultados vários e úteis para a descrição e análise. (SÁNCHEZ, 1995, p.8-9 apud BERBER SARDINHA, 2004, p.18)

Baker (1995), por sua vez, considera a análise de corpus uma fonte de material descritivo-comparativo que pode auxiliar na percepção de diferenças entre a linguagem da tradução e a dos textos originalmente escritos em dada língua.

No presente estudo, utiliza-se um corpus de estudo paralelo formado "(...) de textos fonte e suas respectivas traduções"' (BAKER, 1993, p. 263). O corpus paralelo para investigação deste trabalho é composto por um subcorpus com os TOs em português extraídos das obras de Darcy Ribeiro, assim como por um subcorpus com os respectivos TTs em inglês.

${ }^{5}$ Parallel corpora, that is, corpora of source texts and their translations. 
No tocante aos fraseologismos ou UFs, tomam-se por base os estudos de Casares (1992, p.170), para quem esses componentes linguísticos são "combinação estável de dois ou mais termos, que funcionam como elemento oracional, cujo sentido unitário consabido não se justifica como uma soma do significado dos componentes".

Para Corpas Pastor (2010, p. 125), a fraseologia

[...] engloba todas as combinações formadas por, no mínimo, duas palavras, cujo limite superior se encontra na oração composta, caracterizadas por uma alta frequência de ocorrência na língua e de coocorrência de seus elementos integrantes, além da institucionalização, a estabilidade, a idiomaticidade e a variação que tais unidades apresentam em diferentes graus. ${ }^{6}$

No caso das UFs, a autora (2010, p.126) propõe a seguinte definição: "uma combinação estável de, pelo menos, duas palavras que, conforme as diferentes correntes, terá como limite superior o sintagma ou a oração composta e apresentará como traços inerentes a fixação ou a idiomaticidade por si mesmas, ou então uma combinação de ambos os critérios"?

Assim sendo, ao se trabalhar com conceitos advindos também da Terminologia, salienta-se ser necessário descrever o constructo de unidade fraseológica de especialidade (UFE):

Unidades Fraseológicas de Especialidade: são unidades de significação especializada sintagmáticas, que estão formadas por um núcleo terminológico (Unidade Terminológica simples ou sintagmática) e por um núcleo nominal (nome ou particípio do verbo), que representam as atividades e processos específicos de um domínio.

\footnotetext{
${ }^{6}[. .$.$] engloba todas aquellas combinaciones formadas por al menos dos palabras y$ cuyo limite superior se situa en la oración compuesta, caracterizadas por una alta frecuencia de aparición en la lengua y de coaparición de sus elementos integrantes, así como la institucionalización, la estabilidad, la idiomaticidad y la variación que dichas unidades presentan en diversos grados.

${ }^{7}$ Una combinación estable de al menos dos palabras, que, en virtud de las distintas corrientes, tendrá como limite superior el sintagma o la oración compuesta y presentará con rasgos inherentes la fijación o la idiomaticidad por si solas, o bien una combinación de ambos criterios.
} 
São dependentes de uma área temática, possuem um determinado grau de fixação interna e têm uma frequência relevante nos textos de um domínio de especialidade. ${ }^{8}$ (BEVILACQUA, 2004, p. 28)

Considera-se que o processo tradutório, em muitos casos, envolve uma relação linguística e social constante com vocábulos, ${ }^{9}$ termos ${ }^{10}$ e UFEs, a qual se torna mais regulada e fixa no momento em que se configura a tradução de uma área de especialidade, como no caso deste trabalho, o universo antropológico de Darcy Ribeiro. Para os tradutores que se propõem a trabalhar com a linguagem de especialidade de determinado campo, é interessante conhecer instrumentos apropriados, como corpora especializados, com o objetivo de produzir TTs condizentes com as padronizações da tipologia textual da área a que se dedicam. Nesse contexto, as teorias dos Estudos da Tradução e da Terminologia se cruzam, favorecendo a prática tradutória.

A Terminologia assume importante papel para os Estudos da Tradução, pois fornece a base teórica para a identificação das UFEs da Antropologia que esta pesquisa se propôs a analisar nas obras ensaísticas de Darcy Ribeiro.

\section{Estudos da Tradução Baseados em Corpus}

Tendo como base o desenvolvimento da interdisciplinaridade nos constructos da Tradução, a pesquisadora Mona Baker (1993, 1996, 1999, 2000) elaborou uma proposta teórico-metodológica que assumiu posição de destaque no meio acadêmico. Para a autora:

\footnotetext{
${ }^{8}$ Esta será a definição seguida na análise.

${ }^{9}$ Vocábulo [é um] modelo de realização de palavras que o representam no texto (BARBOSA, 1990, p.233). Palavra é uma unidade do texto e o vocábulo é uma unidade do léxico (BARROS, 2004, p.41).

${ }^{10}[. .$.$] termo é um vocábulo, uma vez que é um modelo de realização lexical no texto.$ Seu caráter de termo se dá pelo fato de que designa um conceito específico de um domínio de especialidade. O conjunto terminológico presente nesse texto constitui, na verdade, um subconjunto do conjunto vocabular do mesmo. Assim, um termo é também um vocábulo, além de ser uma palavra. (BARROS, 2004, p.42).
} 
[Os] textos traduzidos registram eventos comunicativos genuínos e como tais não são nem inferiores nem superiores a outros eventos comunicativos em qualquer língua. Entretanto, eles são diferentes, e a natureza dessa diferença precisa ser explorada e registrada. ${ }^{11}$ (BAKER, 1993, p.234)

Sua perspectiva analítica fundamenta-se em um quadro epistemológico que abrange os principais fatores que compõem o processo tradutório, formulando uma análise reflexiva do ato, do processo e do produto da tradução. A apreciação dos TTs é realizada em seu ambiente de interação e favorece o enfoque comparativo, dentro de um procedimento empirista, de observação de usos em corpora eletrônicos. A pesquisadora propõe uma forma de análise dos dados linguísticos que os vincula não somente aos valores culturais, mas também à própria natureza do TT e dos procedimentos adotados para a Tradução, ou seja, delimita o objeto, bem como o método, para uma investigação científica inovadora e independente.

Laviosa também segue os princípios dos Estudos da Tradução Baseados em Corpus e afirma que

[os] Estudos da Tradução Baseados em Corpus representam uma área de pesquisa que tem atraído um número crescente de pesquisadores entusiastas que acreditam firmemente em seu potencial de fornecer informação para projetos bem elaborados realizados no mundo todo, bem como de reconciliar a pluralidade de necessidades e interesses dentro da disciplina. ${ }^{12}$ (LAVIOSA, 2002, p. 33)

A pesquisadora compreende que a integração dos estudos de Toury aos princípios da Linguística de Corpus de Sinclar (1991) incorre na hipótese de que o princípio da livre escolha no TO é frequentemente substituído pelo princípio idiomático de que existe um padrão na

\footnotetext{
${ }^{11}$ Translated texts record genuine communicative events and as such are neither inferior nor superior to other communicative events in any language. They are however different, and the nature of this difference needs to be explored and recorded.

${ }^{12}$ Corpus-based Translation Studies represent an area of research that is attracting a growing number of enthusiastic scholars who genuinely believe in its potential for informing well thought-out projects throughout the world and for reconciling the plurality of needs and interests within the discipline.
} 
utilização da linguagem. Dessa forma, para Laviosa (2002), ocorre uma motivação racional para as opções adotadas pelos tradutores, a qual pode ser verificada e avaliada por meio de corpora.

O contexto de produção dos textos repercute no processo tradutório de modo que as escolhas e soluções adotadas pelos tradutores são influenciadas pelo status social do texto que estão produzindo. Em sua obra Corpus-based Translation Studies: Theory, Findings, Applications (LAVIOSA, 2002), a estudiosa busca responder questões voltadas aos valores culturais e sociais da tradução, as quais movem as alternativas e as preferências dos tradutores dentro de um conjunto de possibilidades léxico-semânticas.

Baker (1996, p.178) enfatiza que esse tipo de abordagem possibilita uma maior conscientização de que o significado não é independente, mas se dá dentro de um contexto linguístico situacional e social específico. Sendo assim, as análises decorrentes dessa perspectiva deixam de lado o levantamento de características distintivas entre o TT e o TO e permitem, como aponta Camargo (2007, p.32), diferentes investigações sobre o estilo de determinado tradutor ou de corpus que pertencem a diferentes períodos ou a tipos textuais distintos.

\section{O traço da Normalização e o processo de Nominalização na Tradução}

É nessa conjuntura que as pesquisas de Baker (1995, 1996, 1999, 2000) encontram espaço para se consolidarem e para trabalharem com um arcabouço teórico-metodológico amplo e multidisciplinar. A autora segue a hipótese de que a Linguística de Corpus contribui para a identificação de certas características ou traços recorrentes, resultantes da interferência de sistemas linguísticos específicos, os quais se apresentam tipicamente nos TTs, mas não nos TOs (BAKER, 1996, p. 180-184). Esses traços nos são apresentados por Camargo (2007):

(1) Simplificação: tendência em tornar mais simples e de mais fácil compreensão a linguagem empregada na Tradução. Evidências podem ser encontradas nos TTs em relação aos TOs, como repetição de palavras e mudança na pontuação para trazer maior clareza ao enunciado, não necessariamente empregando uma linguagem mais explícita. 
(2) Explicitação: tendência geral em explicar e expandir dados do TO, por meio de uma linguagem mais explícita, mais clara para o leitor do TT.

(3) Normalização ou conservacionismo: tendência para exagerar características da língua materna e para adequarse aos seus padrões típicos.

(4) Estabilização: tendência para a Tradução localizarse no centro de um contínuo, evitando-se os extremos. Diferentemente da normalização, que é dependente da [Língua Meta] LM ao exagerar suas características nos TTs, o processo de estabilização não é dependente nem da LM nem da [Língua Fonte] LF. (CAMARGO, 2007, p. 31-32)

É importante salientar que não há fronteiras definidas entre os traços apontados, de modo que em alguns momentos eles podem sobrepor-se. A simplificação, por exemplo, pode indicar que o tradutor estaria buscando tornar o TT mais simples para o leitor da Cultura Meta; contudo, esses traços também poderiam mostrar que o tradutor procurou adequar o TT às estruturas da LM.

No caso desta investigação, dá-se ênfase à normalização. Para Berber Sardinha (2002, p.18), no processo de normalização, os tradutores tendem a minimizar os aspectos criativos das escolhas lexicais da LF e, em comparação com as opções em LM, revelam alternativas menos marcadas nos TTs.

Além disso, é importante verificar que a normalização estende-se a outros planos linguísticos que não se resumem ao léxico. Para Baker (1996, p. 183), essa disposição do tradutor pode ser influenciada pelo status da LF e da LM, de forma que quanto maior for o "valor" atribuído à LF, menor será a tendência a normalizar o texto. A autora compreende que esse traço é mais evidente no uso de estruturas típicas gramaticais, na pontuação e nos padrões de colocação.

Em adição a essa teoria, Pym $(1993,2000)$ acrescenta duas hipóteses sobre a normalização: a primeira afirma que os tradutores são, de algum modo, inerentemente mais conservadores e menos criativos que os autores; a segunda sugere a existência de restrições cognitivas no processo de tradução que fazem com que os tradutores utilizem algumas das estratégias da normalização de maneira consciente ou inconsciente. $\mathrm{O}$ autor fundamenta tal prerrogativa em possíveis diferenças e limitações 
socioculturais e econômicas que podem ocorrer entre a LF e a LM. Nesse sentido, reconhecendo a pouca difusão da literatura e de textos antropológicos brasileiros traduzidos para o mercado de língua inglesa, acredita-se que os tradutores poderiam sentir-se pressionados a usar "um tipo de inglês 'internacional', que evitasse vocabulário específico de certa região"13 (PYM, 2000). Por conseguinte, a criatividade do tradutor tenderia a ser limitada pelo desejo de procurar uma maior aceitabilidade do público leitor do TT na LM.

Quanto ao fenômeno da nominalização no processo tradutório de UFEs, nota-se que se trata de nomes formados a partir de itens lexicais de origem nas categorias sintáticas de verbo. As nominalizações presentes são determinadas com deverbais, ou seja, são formuladas a partir de expressões de cunho verbalizado no TO. Para Beard (1995), há uma transposição do significado verbal para um lexema semanticamente equivalente de categoria nominal. Por sua vez, Comrie (1976) salienta que se compõem de nomes derivados a partir de verbos, com significados geralmente voltados para ações e processos.

\section{Interrelação entre pressupostos teóricos do Habitus e dos Estudos da Tradução Baseados em Corpus}

Neste contexto de investigação, o ato tradutório constitui-se enquanto processo que caracteriza dada representação social, ou seja, um preenchimento de funções previamente estabelecidas por uma referida comunidade. Dessa maneira, os tradutores atuam sob diferentes condições moderadoras, adotando distintas escolhas lexicais e gramaticais e desenvolvendo produtos marcados socialmente.

Toury (1995) pretende, com base nessa leitura, adotar uma posição sistemática que permita descrever a estrutura normativa da atividade tradutória. Sendo assim, conduz suas pesquisas para a elaboração de um panorama das normas que regulamentam a prática tradutória, principalmente no que diz respeito ao texto como um elemento cultural representativo de um grupo social específico. O autor ainda procura realizar a análise das normas iniciais que fundamentam as escolhas básicas dos tradutores e, com isso, promover padrões específicos

${ }^{13}$ [...] a kind of 'international' English that avoids vocabulary specific of a certain region. 
relacionados aos sistemas de significado das sociedades de partida e de chegada.

Dessa forma, é necessário avaliar e validar os traços de comportamento recorrentes (as normas) em busca de uma padronização (um habitus), como veremos mais adiante no presente trabalho).

As normas são condutas seguidas metodicamente pelos tradutores em dadas situações socioculturais. Ao propor sua observação, Toury $(1978,1995)$ concentra as atenções no TT como objeto de estudo e passa a ter por meta analisar as relações entre a função, o processo e o produto da tradução, considerando as traduções como textos autênticos e não representações de outros textos.

Esta teorização reforça a proposição de que, quando o tradutor se propõe a tarefa de apresentar um conteúdo linguístico que circula dentro de um contexto sociocultural de uma comunidade societária para outra sociedade completamente divergente, esse ator social precisa estar consciente dos contrastes em relação aos hábitos sociais representados nas linguagens. Torna-se pertinente investigar os aspectos culturais de ambos os núcleos humanos e observar as questões semânticas, bem como pragmáticas, que circunscrevem variações ideológicas e interpretativas expressas por diferentes grupos.

O tradutor torna-se pesquisador de uma realidade e procura investigar os significados dos itens sociais e dos vocábulos como formas de nomear valores culturais, combinando, assim, teorias das Ciências Sociais com a análise e a descrição linguística e promulgando maior conhecimento dos fenômenos ocorridos em sociedade, bem como uma ampla conscientização das contextualizações nas quais as palavras são símbolos.

O impacto dos pressupostos apresentados pelos antropólogos possibilitou a formação de uma Sociologia dos Estudos da Tradução, a qual se divide em três recortes principais: o papel do agente social (tradutor); o valor da prática social (traduzir); e o produto social (o TT). Tais investigações podem integrar-se, pois, à conjuntura das análises de Pierre Bourdieu, que, entre os anos de 70 e 80 publicou as obras Esquisse d'une théorie de la pratique (1972), Questions de sociologie (1980), Ce que parler veut dire: L'économie des échanges linguistiques (1982), nas quais apresenta os principais conceitos de suas teorias, a saber: habitus, troca simbólica e capital social. 
No tocante à Tradução, as análises bourdieusianas repercutem na ideia de que a linguagem assume uma posição dentro da relação de trocas em que o léxico constitui-se enquanto bem simbólico (por não apresentar características materiais) com valores adequados à comunicação de cada grupo social. Bourdieu, em sua compreensão sociológica dos fatos linguístico-sociais, acrescenta que, em uma ordem econômica, as trocas de bens da linguagem criam fatores como taxas de câmbio, variações de preço, lucro e prejuízo que seriam atribuídos pelas relações de dominação entre as sociedades envolvidas, constituindo um capital que é social.

Assim, o processo tradutório caracteriza-se como uma atividade agregada de poder, o qual é fundamentado e delimitado por comportamentos padronizados, hierarquizados e valorados socialmente. E os tradutores são motivados por determinados habitus pelos quais se inserem em campos de atuação distintos. De acordo com Bourdieu (1972, 1980), entende-se por habitus um conhecimento adquirido em sociedade que permite a regulação das práticas sociais. Esta consciência integra o conjunto das disposições que constituem a competência para que os agentes (tradutores) tenham acesso a estratégias adequadas e possam obter maiores possibilidades de lucro (sucesso).

O habitus é constituído, na realidade, por todas as medidas, padrões de ação ou percepção que os indivíduos adquirem por meio de sua experiência social. Ao socializarem-se, os homens incorporam maneiras de pensar, sentir e agir, que são sustentadas pelo coletivo. Bourdieu (1972, 1980, 1982, 1983) considera que estas disposições são a fonte de práticas futuras dos indivíduos.

No entanto, o habitus é mais do que apenas o condicionamento que leva a reproduzir mecanicamente o que foi conquistado. Não se trata de um hábito que realizamos automaticamente. As disposições do habitus são os padrões de percepção e ação que possibilitam ao indivíduo produzir um conjunto de práticas adaptadas ao novo mundo social onde ele está localizado, bem como gerar um número infinito de novas práticas. Pode-se, ainda, caracterizá-lo como

(...) um sistema de disposições duráveis e transponíveis que, integrando todas as experiências passadas, funciona em cada momento como uma matriz de percepções, apreciações e ações - e torna possível a realização de tarefas infinitamente diferenciadas, graças às transferências analógicas de esquemas, que permitem resolver os 
problemas da mesma forma, e às correções incessantes dos resultados obtidos, dialeticamente produzidas por esses resultados. (BOURDIEU, 1983, p. 65)

Dessa maneira, no que diz respeito aos contextos linguísticos de uso de UFEs, o habitus compreende-se, neste ambiente, por ser "uma capacidade de utilizar as possibilidades oferecidas pela língua e de avaliar praticamente as ocasiões de usá-las" (BOURDIEU, 1982, p. 66).

\section{Material e método}

Para esta investigação, foi compilado um corpus principal paralelo, composto pelas obras: O processo civilizatório (1968) e $O$ povo brasileiro (1995), de autoria de Darcy Ribeiro; e pelas respectivas traduções para o inglês: The Civilizational Process (1968) e The Brazilian People (2000), realizadas por Meggers e Rabassa, respectivamente.

O levantamento dos dados foi realizado com a utilização das ferramentas WordList e Concord do software WordSmith Tools, as quais facilitam a compilação das UFEs, assim como de seus contextos de uso.

A seleção dos vocábulos organizou-se pela ordem de frequência, ou seja, primeiramente, foram elencadas as cem palavras de maior recorrência em nosso corpus de estudo em LF . Focou-se nas palavras de cunho substantival e verbal, as quais serviram como diretrizes para a escolha dos possíveis candidatos a UFEs que compõem o estudo. Os itens lexicais substantivais e verbais foram priorizados em decorrência de sua maior ocorrência no TO darcyniano, no que tange à terminologia antropológica.

No tocante ao contexto de uso dos vocábulos, utilizou-se a ferramenta Concord para gerar as linhas de concordância com as palavras de busca (ou nódulos). Nesta pesquisa, os nódulos nas listas de concordância correspondem às palavras mais frequentes obtidas por meio do levantamento com a ferramenta WordList. Com isso, verificou-se que os verbos e substantivos presentes entre as cem palavras mais frenquentes apareciam em combinatórias que conduziram à extração de 73 possíveis UFEs, as quais foram destacadas na investigação e passaram a compor a base de análise do processo tradutório.

Feita a compilação do léxico a ser analisado, passou-se a estudar as opções de tradução ocorridas no subcorpus do TT, as quais poderiam representar dissociações decorrentes das diferenças culturais entre a 
sociedade de partida e a sociedade de chegada. O cruzamento dos dados foi realizado a partir dos alinhamentos dos textos com o aplicativo Viewer\&Alligner do mesmo software.

Dessa forma, foram selecionadas as UFEs (que serão apresentadas no próximo subitem deste trabalho) no decorrer da análise dos dados, a fim de exemplificar as possíveis aproximações e distanciamentos entre a linguagem de especialidade em LF e em LM, respectivamente.

Para tanto, utilizou-se o corpus de apoio ${ }^{14}$ formado por dicionários e produções voltados para a terminologia antropológica (BARFIELD, 1997; DICIONÁRIO DE CIÊNCIAS SOCIAIS, 1986; DICIONÁRIO DE SOCIOLOGIA, 1977; ENCYCLOPEDIA OF THE SOCIAL SCIENCES, 1962; OUTHWAITE; BOTTOMORE, 1993). Por meio dessas obras objetivou-se observar as concepções dos conjuntos de termos que compõem as UFEs utilizadas por autor e tradutores, e as relações de sentido que se estabelecem em culturas e sociedades distintas, procurando contemplar o uso de UFEs chaves da Antropologia em LF e em LM, ressaltando as distinções de leitura entre os diversos públicos, assim como a possível reinterpretação cultural de dados da obra de Darcy Ribeiro.

Conclui-se, por meio desta investigação, que os contextos influem de maneira direta na formação dos comportamentos dos tradutores, permitindo-lhes compreender os TTs como textos independentes formulados pelo habitus tradutório profissional.

\section{Análise dos resultados}

Para a análise da tradução das UFEs referentes ao contexto sociocultural antropológico brasileiro presente nas obras darcynianas que compõem o corpus, foram utilizadas as listas de frequência dos TOs e dos TTs com o auxílio da ferramenta WordList.

Ao se verificar as listas, foram selecionadas as palavras mais representativas de base verbal e substantival, conforme exposto no item anterior. Abaixo, apresentam-se as tabelas de 1 a 4, com os verbos e substantivos de maior frequência presentes nos corpora dos TOs e dos TTs.

\footnotetext{
${ }^{14}$ Um corpus de apoio constitui-se de obras de especialidade consultadas para dar amparo à teoria, não havendo necessidade de ser comparável ou paralelo.
} 


\section{TABELA 1}

Lista de frequência dos vocábulos substantivais nas obras em LF

\begin{tabular}{c|c}
\hline Vocábulo substantival em LF & Frequência \\
\hline ÍNDIOS & 459 \\
\hline TRABALHO & 315 \\
\hline POPULAÇÃO & 286 \\
\hline TERRA & 247 \\
\hline ÁREAS & 228 \\
\hline ESCRAVOS & 167 \\
\hline INDÍGENAS & 115 \\
\hline CLASSES & 101 \\
\hline EXPLORAÇÃO & 98 \\
\hline EVOLUÇÃO & 94
\end{tabular}

TABELA 2

Lista de frequência dos vocábulos verbais nas obras em LF

\begin{tabular}{c|c}
\hline Vocábulo verbal em LF & Frequência \\
\hline PRODUZIR & 60 \\
\hline CULTIVAR & 13 \\
\hline TRANSFIGURAR & 12 \\
\hline DESENVOLVER & 10 \\
\hline POVOAR & 7 \\
\hline CIVILIZAR & 5 \\
\hline COLONIZAR & 4 \\
\hline ABOLIR & 4 \\
\hline COLHER & 4 \\
\hline ACULTURAR & 3 \\
\hline
\end{tabular}




\section{TABELA 3}

Lista de frequência dos vocábulos substantivais nas obras em LM

\begin{tabular}{c|c}
\hline Vocábulo substantival em LF & Frequência \\
\hline PEOPLE & 497 \\
\hline INDIANS & 473 \\
\hline LAND & 313 \\
\hline AREAS & 212 \\
\hline SLAVES & 209 \\
\hline LABOR & 191 \\
\hline CULTURE & 167 \\
\hline DEVELOPMENT & 143 \\
\hline EXPANSION & 133 \\
\hline INDIGENOUS & 123
\end{tabular}

TABELA 4

Lista de frequência dos vocábulos verbais nas obras em LM

\begin{tabular}{c|c}
\hline Vocábulo verbal em LF & Frequência \\
\hline TO PRODUCE & 42 \\
\hline TO DEVELOP & 14 \\
\hline TO CULTIVATE & 12 \\
\hline TO ENSLAVE & 4 \\
\hline TO CIVILIZE & 4 \\
\hline TO DOMINATE & 4 \\
\hline TO ABOLISH & 3 \\
\hline TO COLONIZE & 2 \\
\hline TO CAPTURE & 2 \\
\hline TO ACCULTURATE & 1 \\
\hline
\end{tabular}


A partir dos dados apresentados, nota-se uma primeira tendência a ser considerada dentro da prerrogativa do habitus, proposta por Bourdieu (1982) e por Simeoni (1998), para a tradução terminológica, a saber: a de utilizar com maior frequência nominações por meio de substantivos, para designar fatores sociais e culturais da nação brasileira. Na sequência, percebe-se, também, que há a utilização de verbalizações em menor escala, as quais se referem a processos socioculturais que saem de um primeiro plano descritivo de um fato social, sendo transformados em ações, como os conceitos de "transfigurar" (que se origina de "transfiguração"), "civilizar" ("civilização") e "colonizar" ("colonização").

Esses dados permitem considerar que as escolhas léxicoterminológicas darcynianas privilegiam termos associados na forma de UFEs, podendo, o povo brasileiro em formação, compor atuações como "empreender a colonização branqueadora", "ascender da tribalidade à civilização" e "impedir a transfiguração".

A seguir, com base nas informações fornecidas pela ferramenta Concord, apresenta-se o quadro 1, com possíveis UFEs compostas com base nos verbos "produzir", "cultivar", "transfigurar", "civilizar" e "colonizar":

\section{QUADRO 1}

Possíveis UFEs formuladas com base nos verbos de maior frequência nos TOs darcynianos

\begin{tabular}{ll}
\hline PRODUZIR & - Produzir mercadoria exportável \\
- Produzir bens & - Produzir lucros exportáveis \\
- Produzir lucros & - Produzir bens de exportação \\
- Produzir açúcar & - Produzir lucros financeiros \\
- Produzir algodão & - Produzir cana \\
- Produzir colheitas de mocó & - Produzir gêneros exóticos de exportação \\
- Produzir cerâmica & - Produzir crioulos \\
- Produzir mercadoria & \\
\hline CULTIVAR & \\
- Cultivar terras arrendadas & \\
- Cultivar roçados & \\
- Cultivar roças de subsistência & \\
- Cultivar rocinhas & \\
\hline
\end{tabular}


TRANSFIGURAR

- Transfigurar povos autóctones

- Transfigurar etnias

- Transfigurar nações

CIVILIZAR

- Civilizar selvagens

- Civilizar curumins

- Civilizar gente

- Civilizar os índios

COLONIZAR

- Colonizar povos

É possível notar que o autor constrói, sob o amparo dos verbos, um universo social ativo e modificador, pautado no "lucro", na "escravidão" e no "domínio".

Verifica-se, ainda, que faz parte da concepção do habitus, adquirida e praticada dentro da área de especialidade, o reuso de conceitos-chave da Antropologia, como, por exemplo, a ideia de "povo", "etnia" e "índio". Os vocábulos de ordem substantival de maior ocorrência interligam-se com os vocábulos verbais, construindo valorações e procedimentos. No tocante à atividade tradutória, Meggers e Rabassa aproximam suas traduções dos atos efetivos propostos para o entendimento do contexto nacional e para o desenvolvimento de uma sociedade nova. O quadro 2 mostra as UFEs formuladas a partir dos verbos mais frequentes nos TTs. 


\section{QUADRO 2}

Possíveis UFEs formuladas com base nos verbos de maior frequência nos TTs darcynianos

\section{TO PRODUCE}

- To produce profits

- To produce new ethno-national configurations ${ }^{15}$

- To produce surpluses ${ }^{16}$

- To produce more mamelucos ${ }^{17}$

- To produce merchandise

- To produce exportable profits

- To produce exportable merchandise

TO CULTIVATE

- To cultivate the land

- To cultivate plots

- To cultivate rented land

- To cultivate a subsistence plot

- To cultivate a small plot

TO CIVILIZE

- To civilize the country

- To civilize savages

- To civilize urchins ${ }^{18}$

- To civilize Indians

TO COLONIZE

- To colonize the lands

TO CAPTURE

- To capture Indians

As relações de sentido estabelecidas mostram que os tradutores se apropriaram das verbalizações de Darcy Ribeiro e as recolocaram em novas situações, como em "to produce new ethno-national configurations" e "to civilize urchins". Revelam, com isso, uma possível intensificação da utilização de verbos dentro do léxico de especialidade, distinguindo

\footnotetext{
${ }^{15}$ Produzir novas configurações etno-nacionais

${ }^{16}$ Produzir excedentes

${ }^{17}$ Produzir mais mamelucos

${ }^{18}$ Civilizar curumin
} 
os TTs dos TOs, como, por exemplo, na conjectura do "to produce more mamelucos".

Na América Latina, o "mameluco" é também designado como "caboclo" e tem sua formação identitária com a "mestiçagem". Por volta dos séculos XVII e XVIII, o termo referia-se aos bandos de caçadores de "escravos" fugidos, geralmente organizados por colonizadores. No Brasil, a menção ao termo relaciona-se diretamente aos constructos de "capitães do mato" e de "jagunços", os quais, por sua vez, representam sujeitos sociais imersos em um contexto escravocrata e senhorial. Verifica-se, ainda, que a denominação era dada, geralmente, aos filhos de homens europeus com nativas indígenas, tendo sido introduzida pelos portugueses durante o período das "bandeiras" e da expansão territorial.

No que concerne às escolhas apresentadas para os TTs, observa-se o empréstimo do termo em LF, buscando evidenciar os comportamentos e os ambientes sócio-históricos da Cultura Fonte. Ao optar por não traduzir o termo, os tradutores apresentam a formação de um novo grupo humano mestiçado no Brasil e também as possíveis ressignificações do uso, como, por exemplo, a proposição de um núcleo social com propósitos de dominação territorial, ora pela interação militarizada e dominadora do contexto europeu ora pela visão exploratória expansionista de um Brasil em desenvolvimento e formado por diversos processos de socialização de povoações brancas, negras e índias.

Observa-se, ainda, que não existe uma opção de tradução para a conceituação de "transfigurar" de modo que os tradutores parecem ter optado por alterar o significado da UFE e por compor novas compreensões, possivelmente confirmando a hipótese de que a base comportamental terminológica tradutória constitui-se da verificação dos reusos e das combinatórias presentes nos TOs, da apropriação das significações e da reprodução e ressignificação conceitual.

Para confirmar tal prerrogativa, verificam-se as recorrências a determinados termos e a suas combinatórias. Como mencionado, a Antropologia tem a tendência a apresentar concepções na forma de substantivos, levando os tradutores, por conseguinte, a optar por alterar as terminologias dos TTs e por retomar o princípio primário, ou seja, a categorização com base em termos nominativos.

Encontra-se tal conduta como parte integrante do habitus tradutório. 
Como forma de compreender este comportamento, selecionamos as UFEs formuladas com as palavras mais frequentes como nódulos de busca. Os quadros 3 e 4, a seguir, fundamentam-se nos termos já consagrados $^{19}$ pela área de especialidade e apresenta as coocorrências com as principais ações tomadas em relação a esses conjuntos lexicais nos TOs e nos TTs:

\section{QUADRO 3}

Possíveis UFEs formuladas com base nos termos de maior frequência nos TOs darcynianos

\footnotetext{
ÍNDIOS

- Exterminar índios

- Civilizar índios

- Amansar índios

- Destribalizar índios

- Desalojar índios

- Capturar índios silvícolas

- Sujigar índios

- Caçar índios

- Avassalar os índios

- Explorar índios

- Vender índios

- Catequizar índios

- Escravizar os índios
}

\section{POPULAÇÃO}

- Integrar a população

- Assolar a população

- Transladar a população

- Dominar populações rurais

- Subjugar a população

- Esgotar a população indígena

- Desmoronar a população

- Reavaliar a população indígena

- Dizimar as populações indígenas

- Integrar as populações rurais

- Desenvolver a população brasileira

\footnotetext{
${ }^{19}$ Os termos são considerados consagrados por terem sido utilizados em consonância conceitual por diversos Cientistas Sociais, bem como por terem sido dicionarizados.
} 


\section{TERRAS}

- Apropriar as terras devolutas

- Ceder terras de cultivo

- Invadir terras

- Ocupar terras de ninguém

- Apropriar terras cultiváveis

- Alocar terras de cultivo

- Ocupar terras

- Conceder terras

- Arrendar terras

ESCRAVOS

- Vender escravos

- Exportar escravos

- Incorporar negros escravos

- Apresar escravos

- Caçar escravos

- Prear escravos

- Capturar escravos

- Perseguir escravos

- Aliciar escravos

- Importar escravos

\section{INDÍGENAS}

- Exterminar indígenas

- Exterminar tribos de indígenas

- Contingenciar os indígenas

- Chacinar indígenas 


\section{QUADRO 4}

Possíveis UFEs formuladas com base nos termos de maior frequência nos TTs darcynianos

\section{INDIANS}

- To teach Indians

- To confess Indian men

- To de-Indianize the Indians

- To civilize Indians

- To Hunt down the Indians

- To contaminate surrounding Indians

- To capture integrated Indians

- To enslave Indians
- To catechize the Indians

- To hunt Indians

- To captive Indians

- To exterminate Indians

- To confront hostile Indians

- To herd Indians for the slave trade

- To confine Indians

- To integrate the Indians

- To capture Indians

\section{POPULATION}

- To Christianize the population

- To mobilize the population

- To exploit populations

- To multiply population contingents

- To incorporate populations

- To conquer populations

- To examine populations

- To subjugate populations

- To slaughter mixed-blood populations

- To govern a population

- To lead the population

- To conquer populations

- To examine populations

- To subjugate populations

- To slaughter mixed-blood populations

- To govern a population

- To lead the population

\section{LANDS}

- To allocate cultivated lands

- To cultivate the lands

- To colonize the lands

- To exploit the lands

\section{SLAVES}

- To capture slaves

- To hunt slaves

- To obtain slaves

\section{INDIGENOUS}

- To displace indigenous population

- To organize indigenous lives

- To reduce indigenous population 
Há uma aparente redução de correlações estabelecidas entre os termos e as ações que os circunscrevem nos TTs, o que pode direcionar a interpretação sobre a formação do habitus tradutório para a proposta de que os tradutores fundamentam suas escritas de maneira independente, caracterizando uma nova leitura terminológica no que concerne às UFEs, principalmente.

Os diferentes graus de reuso nas obras original e traduzida representam a maneira como os elementos da abordagem darcyniana circulam entre a comunidade nacional e a amplitude que alcançam dentro dos meios de divulgação para o público alvo de LM. A análise da variação entre o uso das UFEs pelo autor e pelos tradutores pode conduzir à ideia de que Meggers e Rabassa procuraram colocar em evidência traços da Cultura Brasileira com uma ênfase maior para a LM do que para a LF. Nota-se, por exemplo, que o termo "índios" e seu correspondente Indians apresentam os maiores índices nos TOs e nos TTs. Entretanto, na obra traduzida, a frequência em relação a questões sociais comuns ao Brasil é elevada em 14 vezes mais que no original. ${ }^{20}$

O diálogo bastante próximo estabelecido entre TOs e TTs auxilia os objetivos esboçados por Darcy Ribeiro desde o primeiro momento de sua produção teórica, ou seja, o de permitir a reavaliação do impacto da influência europeia na formação dos povos neolatinos, desconsiderando certos padrões do campo ou sistema e passando a reavaliá-los sob a ótica do colonizado e não mais do colonizador. De acordo com Darcy Ribeiro, o processo tradutório na direção português $\rightarrow$ inglês corresponderia a uma primeira resposta da relevância que a Antropologia Brasileira assume para os estudiosos da "cultura" no mundo. O trabalho com os índices de frequência permite corroborar essa perspectiva, visto que o tradutor manteve a mesma vivacidade e o mesmo caráter contestador do contexto no qual o autor escrevia. Pode-se inferir, dessa forma, que seu comportamento tradutório adequa-se ao habitus antropológico.

No entanto, embora essa possível identificação teórico-tradutor tenha sido clara, no tocante às coocorrências com verbos, não se pode desconsiderar as variações de conceituação presentes nos itens lexicais e a alteração no grau de significação de um termo que essas mudanças de "cenário" podem causar. Assim sendo, a imagem do "índio" (Indian), no Dictionary of Anthropology (1961) remete, primeiramente, à questão do vínculo ao território americano (desconsiderando a existência de

${ }^{20}$ Contraste entre os totais de ocorrências nos TOs e nos TTs. 
grupos semelhantes em outras regiões do mundo) e, logo em seguida, à conceituação de um tronco racial mongólico caracterizado pela formação de um grupo de indivíduos de pele escura, face arredondada, cabelos lisos, corpo sem pêlos e alguns prognatismos. A definição no dicionário de língua inglesa enfatiza, ainda, a relação entre os tipos sanguíneos destes povos, salientando a presença maior de pessoas de sangue tipo A. Caracteriza-se também o período de chegada ao novo mundo por volta de 20.000 anos atrás e, finalmente, ressalta-se a formulação do nome Indians após o equívoco terminológico de Colombo ao confundir os continentes quando de sua viagem às Índias. A mesma obra de referência apresenta a definição de "índio" como sendo um descendente dos grupos pré-conquistadores da América Latina, os quais preservam a linguagem e os costumes anteriores à chegada dos europeus, por exemplo, os Tarascan do México central.

O Dicionário de Antropologia: do homem primitivo às sociedades actuais (1983), por sua vez, detalha a constituição de cada grupo indígena já estudado, salientando as principais características de cada um. $\mathrm{O}$ verbete inicia-se com os "índios da América Latina" (Latin American Indians) e aponta que o continente americano oferece grande variedade humana, que vai desde as tribos indígenas, que em certas regiões da Amazônia ainda hoje se mantêm fora do alcance do homem branco, até os índios que estão integrados à nova sociedade. Distingue: 1) as regiões que foram os berços das grandes civilizações pré-colombianas desaparecidas, mas das quais subsistem a recordação, as línguas e as mitologias; 2) os Impérios Inca, Maia e Asteca; 3) as regiões tropicais e subtropicais da Guiana e da Amazônia onde sobrevivem numerosas tribos; e 4) as regiões da América do Norte, onde vivem alguns povos como os Apaches, os Navajos, os Yavapai e os Walapai.

Desse modo, a relação que se estabelece na memória do povo brasileiro ao se evocar o conceito de "índios" vai além da proposta de um grupo racial específico. Na concepção de Darcy Ribeiro, trata-se de um dos núcleos constituintes do coletivo nacional, integrado ao Brasil pela absorção e dominância de elementos da mística, da culinária, dos costumes, do vestuário e, em especial, da linguagem.

A perpectiva eurocêntrica, no entanto, concebe o Indian, assim como o Negro, Niger, Black, mulatto e mestizo, mais por suas feições e marcas genéticas de diferença do que por seus valores e crenças, os quais são assimilados pelos povos de poder civilizador. A questão que se 
estabelece nesta dicotomia entre os significados do conceito de "índio" em LF e LM é a de que a constituição do campo antropológico, essencial para a compreensão das sociedades modernas, ilustra o histórico capitalista e colonialista imperante na língua e na terminologia cultural.

Nas UFEs utilizadas pelo autor, notamos a relação de dominação estabelecida sobre esse sujeito social brasileiro, como em: "exterminar índios", "destribalizar índios", "sujigar índios", "caçar índios" e "escravizar os índios". O processo tradutório também contextualiza situações de investida do povo branco sobre os indígenas, nas fraseologias: To capture integrated Indians; To enslave Indians; To confront hostile Indians; To herd Indians for the slave trade; e To confine Indians.

Embora o campo léxico-terminológico que envolve e dá suporte à Antropologia pareça estar vinculado a elementos de significância de sobreposição de populações, autoridade e mando de um grupo sobre o outro, é possível verificar que não há uma total correspondência entre as UFEs formuladas, o que denota que os tradutores possivelmente optaram por recorrer a distintos aspectos do habitus tradutório.

Reconhece-se, então, que ocorre a retomada da nominalização e inclui-se esse fenômeno como elemento integrante da conduta pertinente ao ato de traduzir, favorecendo não somente uma releitura do texto, mas também empregando uma forma "confirmação" do fato social, uma vez que passa do plano da atividade para o plano existencial em si, podendo ser definido e considerado dentro da terminologia da área.

Foram selecionadas, no quadro 5, algumas das UFEs em que ocorre essa possível reformulação conceitual e esse traço do comportamento dos tradutores:

\section{QUADRO 5}

Nominalização na tradução de UFEs para a língua inglesa

\begin{tabular}{c|c}
\hline TOs & TTs \\
\hline Integrar Massas Marginais & Integration of marginal groups \\
\hline Transfigurar as Etnias Originais & Transformation of earlier ethnos \\
\hline Desenvolver Núcleos Urbanos & Development of urban nuclei \\
\hline Colonizar Povos & Colonization of people \\
\hline Produzir Gêneros Exóticos de Exportação & Production of exotic items for export \\
\hline
\end{tabular}


Entende-se, na presente pesquisa em um corpus de Antropologia, que há a formação de UFEs como combinatórias de palavras promovidas de maneira a arranjar significados que organizam as categorias de eventos sociais, culturais e políticos dentro do advento da disposição da terminologia da Antropologia.

Dentro das prerrogativas da conduta tradutória, nota-se o que Bourdieu (1980) convencionou chamar de trocas simbólicas. Se o léxico é entendido como um capital, as opções de tradução e as alterações promulgadas pelos TTs repercutem de maneira a gerar valores e interpretações distintas para o público alvo, constituindo uma leitura diferenciada com relação ao objeto em análise. Conforme verifica-se na investigação, a terminologia em Ciências Sociais apresenta alta flexibilidade e os padrões de colocação entre verbos e substantivos também são bastante alternáveis; contudo, há a tendência a seguir-se uma rotina de escolhas, o que, de certa forma, norteia as compreensões sociológicas dos fatos linguísticos.

O ato de "transfigurar", por exemplo, está diretamente vinculado ao ideário de "etnia" e se perpetua, na obra darcyniana, também sob a forma da "transfiguração étnica". Para o teórico (1995), tal fenômeno constitui-se como um:

[...] processo através do qual os povos, enquanto entidades culturais, nascem, se transformam e morrem. Tivemos oportunidade de estudá-lo tanto por observação direta, quanto por reconstituição histórica do impacto da civilização sobre as populações indígenas brasileiras no correr dos séculos; reconstituindo suas várias instâncias. Um povo já configurado resiste tenazmente à sua transfiguração, mas o faz precisamente mudando ao assumir aquelas alterações que viabilizam sua existência dentro do contexto em que ele interage. Quatro são as instâncias básicas da transfiguração, simultâneas ou sucessivas. Primeiro, a biótica, pela qual os seres humanos, interagindo com outras forças vivas, podem transfigurarse radicalmente.[...] Uma segunda instância é a ecológica, pela qual os seres vivos, por coexistirem, afetam-se uns aos outros em sua forma física, em seu desempenho vital. [...] A terceira instância da transfiguração étnica é a econômica, que, convertendo uma população em condição de existência material de outra, em prejuízo de 
si própria, pode levá-la ao extermínio.[...] Uma última instância da transfiguração é a psicocultural, que pode dizimar populações retirando-lhes o desejo de viver, como ocorreu com os povos indígenas que se deixaram morrer por não desejar a vida que se lhes ofereciam. (RIBEIRO, 1995, p.257).

Em sua primeira obra, o antropólogo procura definir a transfiguração de "tribos chaquenhas" e "tribos de lavradores da floresta tropical", entre outros grupos, promovendo a reestruturação teórica da formação de um "povo novo" latino-americano, ora pelo testemunho ora pelo transplante. Para tanto, insere questões prévias, analisadas por teóricos europeus, e as adequa ao conteúdo do território em investigação. Ao contrário de outros estudiosos, Darcy Ribeiro ressalta a importância dos elementos de "cultura", "economia", "geografia" e "sociedade" na América do Sul para a formação da "estrutura societária" neste continente. É neste sentido que vocábulos como "capatazia", "cerrado", "mestiço" e "roçado" passam a fazer parte de um conjunto léxico de especialidade, marcando formas de interação humana, territórios e modo de produção típicos da região enaltecida pela teoria do autor.

Em muitos aspectos os tradutores parecem tomar por habitus o reuso de vocábulos da língua geral para descrever aspectos bastante restritos da sociedade brasileira. Nesse âmbito, associam dois elementos principais do comportamento evidenciado na análise, a nominalização atrelada à normalização.

Assim, verifica-se que os tradutores alteraram o constructo de "transfigurar" por transformation, esbarrando-se em uma alteração de sentido da UF. Transformation, de acordo com o Oxford English Dictionary (1961), significa "passar por mudanças, modificações e metamorfoses", o que restringe a compreensão da UFE correlata. Além de retirar o procedimento do plano de atuação e de transformá-lo em um acontecimento, há, também, uma espécie de simplificação do sentido e uma interrelação com o contexto que se apresenta de maneira distintiva, confeccionando um quadro teórico, por vezes novo, senão distante do TO. 


\section{QUADRO 6}

Contexto da formação de possíveis UFEs a partir do verbo "transfigurar" e escolhas tradutórias de Meggers e Rabassa ${ }^{21}$

Integraram-se nela, ao transfigurar sua etnia original por um processo de sucessão ecológica, provocado por um alude imigratório intencionalmente conduzido, os argentinos e os uruguaios.

After a transformation of their earlier ethnos as a result of their encouragement of mass immigration, Argentina and Uruguay also entered this category.

Mas, simultaneamente, inovaram o antigo modelo, complementando-o, primeiro, com colonizações mercantis, na forma de entrepostos comerciais implantados em países longínquos, com os quais não se pretendia transfigurar os povos autóctones, mas tão somente traficar com eles, e, mais tarde, com Colônias de Povoamento, estabelecidas através da transladação de populações européias para além-mar.

They modified the old model, however, by initiating programs of mercantile colonization involving the establishment of trading posts in distant countries to maintain commercial relations with the indigenous populations rather than to transform them. Later, Immigrant Colonies were created by the transplantation of Europeans across the seas.

Há, conforme exposto, uma recolocação do TT, um refazer o léxico-terminológico e um enquadramento dos termos, conceitos e UFEs dentro de novas proposições, o que faz do tradutor um agente operante na concepção de novas terminologias. A seguir, apresenta-se o quadro 7 em que se encontram exemplos de escolhas tradutórias que perfazem a normalização no tocante aos verbos utilizados nos TTs:

$$
\text { QUADRO } 7
$$

Normalização no processo tradutório de UFEs em Meggers e Rabassa

\begin{tabular}{c|c}
\hline TOs & TTs \\
\hline Apresar escravos & To capture slaves \\
\hline Colher as roças & To plant garden plots \\
\hline Cultivar rocinhas & To cultivate a small plot \\
\hline Subjugar caudilhos & To subdue local leader \\
\hline Explorar seringais & To exploit native rubber trees \\
\hline
\end{tabular}

${ }^{21}$ As escolhas apresentadas foram tomadas pelos dois tradutores do corpus em estudo. 
Observou-se que a normalização representa um dos elementos frequentes entre os traços do habitus tradutório. Essa conduta, assim como aquelas apresentadas anteriormente, fundamentam a recorrência ao uso de palavras comuns (advindas da Língua Geral), principalmente quando o tradutor depara com UFs, termos e vocábulos de ordem cultural, os quais podem causar estranhamento em LM.

Nos exemplos acima, as noções de "apresar" (apresamento); "roça"; "caudilho" e "seringais" estão vinculadas ao universo colonial brasileiro. Sabe-se que o aprisionamento dos indígenas e negros esteve atrelado ao constructo de "escravidão" e ao contexto sócio-histórico brasileiro, o qual se configurou por intensa fuga do trabalho forçado (muitas vezes nos seringais), levando à formação de um grupo humano novo, os "capatazes", e à elaboração de um fenômeno próprio, a "capatazia". Esses fatores se organizam de tal forma que os homens que apresam os fugitivos têm, por sua vez, o respaldo dos "caudilhos".

O "caudilhismo", de acordo com o Dicionário de Ciências Sociais (1989), representa um sistema político, social e mesmo cultural que supõe o agrupamento de uma sociedade em torno de uma pessoa, o "caudilho", o qual, como um cacique, é considerado possuidor de certas qualidades pessoais, tais como ser um homem culto, preparado, inteligente e rígido.

Sendo assim, os tradutores recompõem os elementos dessa comunidade e apresentam os fatos sociais, os fenômenos culturais, os agentes de formulação e de interação humana com outros valores de troca. Descrevem a busca pelos "escravos" como um processo de captura (to capture), deixando de observar o complexo entremeio social que se estabelece com a preia.

No mesmo âmbito, ao traduzir o termo "caudilhos" pelo termo sintagmático local leader; e "seringais" por rubber trees, constroem-se e reconstroem-se significados e revela-se o dialogismo entre o TO e o TT, de modo que Meggers e Rabassa depreendem, do conjunto léxico darcyniano, conhecimento para elaborar novos conceitos ou para tornálos mais normalizados e simplificados.

A tradução das UFEs da Antropologia de Darcy Ribeiro mostra que os tradutores mantêm estreita relação com o TO, embora se possa observar que os TTs fomentam funções sociais distintas amoldadas à cultura e sociedade de chegada.

A partir dos exemplos apresentados, observa-se que o trabalho dos tradutores revela a elaboração de um habitus na tendência de permitir 
a introdução de novos contextos e de novas abordagens, considerando ainda os sentidos presentes na própria linguagem.

Sendo assim, considerando que o objetivo dos textos darcynianos foi explorar a formação de um povo novo no Brasil, é bastante coerente que os TTs tendam a ter um grau de normalização e de nominalização maior, visto que há UFs culturalmente marcadas, associadas a uma terminologia típica da história nacional. Vale ressaltar que essas UFEs não encontram correspondência total na LM, sendo esse o fator que faz com que os tradutores adotem normalização e nominalização.

Nota-se, assim, que o habitus tradutório mostra-se mais próximo das questões pertinentes à área de especialidade, havendo uma adequação de características culturais e mesmo terminológicas nos textos de Meggers e de Rabassa, bem como uma reflexão sobre as opções lexicais que se apresentam em língua inglesa, de modo que os tradutores recorrem à explicação e à explicitação dos constructos e ideários darcynianos por meio do uso de mais substantivos e de palavras do vocabulário de uso geral das línguas, os quais facilitam a compreensão das conceituações.

\section{Considerações finais}

Verificamos que o software WordSmith Tools, por meio de suas ferramentas, facilita consideravelmente a análise de uma grande quantidade de dados, obtidos de maneira muito mais rápida e exata do que manualmente.

O uso de corpora permitiu observar que UFEs e também os termos que as constituem apresentam possibilidades de diferentes correspondentes em língua inglesa, havendo variação de uso nas escolhas lexicais, evidenciando tentativas de apresentar ao público alvo a versatilidade da sociedade no Brasil e, assim, desenhar o contexto em que eles representam as diferentes facetas da cultura e língua brasileiras.

Como mencionado anteriormente, esses fatores favoreceram a observação de um comportamento recorrente por parte dos tradutores, o qual permitiu trabalhar as questões sociais envolvidas no processo e no produto tradutório (TTs), por meio da verificação das escolhas terminológicas dos tradutores com o auxílio da teoria e das ferramentas da Linguística de Corpus.

Ao analisar estes elementos, nota-se que a Tradução constituise enquanto ato social, perpassando fatores linguísticos e atribuindo às 
palavras, e mais precisamente aos termos, valores a serem negociados entre as comunidades de partida e de chegada. Por fim, partindo da terminologização das ideologias sociais por meio da qual Darcy Ribeiro propunha a constituição de uma investigação cultural nacionalista por pesquisadores formados no país, observa-se como seria possível formular um habitus para a Antropologia Brasileira. Nesse sentido, ao se trabalhar com os textos darcynianos, embora tenha-se um corpus de obras ensaísticas do autor, é possível verificar um comportamento para as traduções antropológicas de modo geral, na direção português $\rightarrow$ inglês, uma vez que o autor representa importante base para a formação dos conceitos e terminologias utilizados no Brasil pelos demais autores das Ciências Sociais.

Assim, após depreenderem-se os constituintes dessa conduta do autor para sua subárea de especialidade, com base nas teorias propostas por Bourdieu (1980), Simeoni (1998, 2007) e Gouanvic (2005), notamse quais foram os fatores observados pelos tradutores para compor seus comportamentos e, consequentemente, o habitus tradutório.

\section{Referências}

BAKER, M. In other words: a coursebook on translation. Londres: Routledge, 1992. doi.org/10.4324/9780203327579.

BAKER, M. Corpus linguistics and translation studies: implications and applications. In: BAKER, M.; FRANCIS, G.; TOGNINI-BONELLI, E. (Ed.). Text and technology: in honour of John Sinclair. Amsterdam: Jonh Benjamins, 1993. p. 233-250. doi.org/10.1075/z.64.15bak.

BAKER, M. Corpora in translation studies: an overview and some suggestions for future research. Target, Amsterdam, v.7, n. 2, p. 223-243, 1995. doi.org/10.1075/target.7.2.03bak.

BAKER, M. Corpora in translation studies: the challenges that lie ahead. In: SOMERS, H. (Ed.). Terminology, LSP and translation studies in language enginnering: in honour of Juan C. Sager. Amsterdam: John Benjamins, 1996. p. 177-186. doi.org/10.1075/btl.18.17bak.

BAKER, M. Linguística e estudos culturais: paradigmas complementares ou antagônicos nos estudos da Tradução? In: MARTINS, M. A. P. (Org.). Tradução e multidisciplinaridade. Rio de Janeiro: Lucena, 1999. p. 15-34. 
BAKER, M. Towards a Methodology for investigation the style of literary translation. Target, Amsterdam, v. 12, n. 2, p. 241-266, 2000. doi.org/10.1075/target.12.2.04bak.

BARBOSA, M.A. Considerações sobre a estrutura e funções da obra lexicográfica: metodologia, tecnologia e condições de produção. In: COLÓQUIO DE LEXICOLOGIA E LEXICOGRAFIA, 1990, Lisboa. Actas... Lisboa: Universidade Nova de Lisboa, 1990. p. 229-241.

BARFIELD, T. The Dictionary of Anthropology. Oxford: Blackwell Publishing, 1997.

BARROS, L.A. Curso básico de Terminologia. São Paulo: USP, 2004.

BEARD, R. Lexeme-morpheme base morphology. Albany: SUNY Albany Press, 1995.

BERBER SARDINHA, T. Corpora eletrônico na pesquisa em tradução. Cadernos de Tradução, Florianópolis, v. 9, n. 1.p. 15-60, 2002.

BERBER SARDINHA, T. Linguística de corpus. São Paulo: Manole, 2004.

BEVILACQUA, C. R. Unidades fraseológicas especializadas eventivasdescripción y reglas de formación en el ámbito de la energía solar. 2004. Tese (Doutorado) - IULA, Universidade Pompeu Fabra, Barcelona, 2004.

BOURDIEU, P. Esquisse d'une théorie de la pratique, précédé de trois études d'ethnologie kabyle. Genève: Droz, 1972. doi.org/10.3917/droz. bourd.1972.01.

BOURDIEU, P. Questions de sociologie. Paris: Éd. de Minuit, 1980.

BOURDIEU, P. Ce que parler veut dire. L'économie des échanges linguistiques. Paris: Fayard, 1982.

BOURDIEU, P. Esboço de uma teoria de prática. In: ORTIZ, R. Pierre Bourdieu. São Paulo: Ática, 1983.

CAMARGO, D. C. Metodologia de pesquisa em tradução e linguística de corpus. São Paulo: Cultura Acadêmica; São José do Rio Preto: Laboratório Editorial, 2007. (Coleção Brochuras, v.1. 65p.)

CASARES, J. Introducción a la lexicografía moderna. Madri: Editorial CSIC-CSIC Press, 1992. 
COMRIE, B. Aspect: An introduction to the study of verbal aspect and related problems. Cambridge university press, 1976.CORPAS PASTOR, G. Diez años de investigación en fraseología: Análisis sintácticosemánticos, contrastivos y traductológicos. Madrid: Iberoamericana, 2010.

DICIONÁRIO de Ciências Sociais. Rio de Janeiro: Editora Fundação Getúlio Vargas, 1986.

DICIONÁRIO de Sociologia. 7. ed. Porto Alegre: Ed. Globo, 1977.

ENCYCLOPEDIA of the Social Sciences. New York: Macmillan, 1962.

GOUANVIC, J. Pour une sociologie de la traduction: le cas de la littérature américaine traduite en France après la Seconde Guerre mondiale (1945-1960). In: SNELL-HORNBY, M.; JETTMAROVÁ, Z.; KAINDL, K. (Ed.). Translation as Intercultural Communication: selected papers from the EST Congress Prague. Amsterdam; Philadelphia: John Benjamins, 1995. p. 33-44.

GOUANVIC, J. Sociologie de la traduction: la science-fiction américaine dans l'espace culturel français des annés 1950. Arras: Artois Presses Université, 1999.

GOUANVIC, J. The Stakes of Translation in Literary Fields. Across Languages and Cultures, Budapeste, v. 3, n. 2, p. 159-168, 2002.

GOUANVIC, J. A bourdieusian theory of translation, or the coincidence of practical instances: field, "habitus", Capital and "Illusio". The Translator, v. 11, n. 2, p. 147-166, 2005. doi.org/10.1080/13556509.20 05.10799196.

LAVIOSA, S. Corpus-based translation studies: theory, findings, applications. Amsterdã; Atlanta: Rodopi, 2002.

OUTHWAITE, W.; BOTTOMORE, T. (Org.). The Blackwell Dictionary of Twentieth-Century Social Thought. Oxford: Blackwell Publishers, 1993.

OXFORD English Dictionary. Clarendon Press, 1961.

PYM, A. Epistemological problems in translation and its teaching. Calaceut: Editions Caminade, 1993. 
PYM, A. On Cooperation. Intercultural faultlines: research models in Translation Studies I: textual and cognitive aspects. Manchester: St. Jerome, 2000. p.181-192.

RIBEIRO, D. Os índios e a civilização. Rio de Janeiro: Civilização Brasileira, 1970.

RIBEIRO, D. O processo civilizatório. Rio de Janeiro: Editora Civilização Brasileira, 1968.

RIBEIRO, D. The civilizational process. Translated from Portuguese by Betty M. Meggers. Washington: Smithsonian Institution Press, 1978.

RIBEIRO, D. Os índios e a civilização: a integração das populações indígenas no Brasil moderno. São Paulo: Vozes, 1982.

RIBEIRO, D. Suma etnológica brasileira. Petrópolis: Vozes; Financiadora de Estudios e Projetos, 1987.

RIBEIRO, D. O povo brasileiro: a formação e o sentido do Brasil. São Paulo: Companhia das Letras, 1995.

RIBEIRO, D. The Brazilian People: formation and meaning of Brazil. Translated from Portuguese by Gregory Rabassa. Gainesville: University Press of Florida, 2000.

SAGER, J. In search of a foundation: towards a theory of the term. Terminology, John Benjamins, v.5, p. 41-57, 1998. doi.org/10.1075/ term.5.1.05 sag.

SIMEONI, D. The Pivotal Status of the Translator's Habitus. Target, Amsterdam, v. 10, n. 1, p. 1-39, 1998. doi.org/10.1075/target.10.1.02sim.

SIMEONI, D. Translation and Society: The Emergence of a Conceptual Relationship. In: ST-PIERRE, P.; KAR, P.C. In Translation: reflections, refractions, transformations. Amsterdam; Philadelphia: John Benjamins, 2007. p. 13-27. doi.org/10.1075/btl.71.05sim.

SINCLAIR, J. M. Corpus, concordance, collocation. Oxford: Oxford, 1991.

TOURY, G. The nature and role of norms in literary translation. In: HOLMES, J.; LAMBERT, J; VAN DEN BROECK, R. (Ed.). Literature and translation. Leuven: ACCO, 1978. p. 83-100 [Versão revisada em VENUTI, L. (Ed.). The translation studies reader. London; New York: Routledge, 2000. p. 205 -218]. 
TOURY, G. Translation, literary translation and pseudotranslation. Comparative Criticism, Cambridge, v. 6, p. 73-85, 1984.

TOURY, G. What are descriptive studies in translation likely to yield apart from isolated descriptions? In: LEUVEN-ZWART. K.; NAAIJKENS, T. (Ed.). Translation Studies: The state of the Art. Proceedings of the First James S Holmes Symposium on Translation Studies. Amsterdam Atlanta: Ropodi. Approaches to Translation Studies, v.9, p. 179-192, 1991.

TOURY, G. Descriptive Translation Studies and Beyond. Amsterdam and Philadelphia: John Benjamins, 1995. doi.org/10.1075/btl.4.

TOURY, G. A Handful of Paragraphs on Translation and Norms. In: SCHAFFNER, C. (Ed.) Translation and Norms. Great Britain: Short Run Press, 1999. p. 9-31. 